\title{
Contrasting roles of IL-22 and IL-17 in murine genital tract infection by Neisseria gonorrhoeae
}

\section{Brandon Feinen ${ }^{\dagger}$ and Michael W. Russell *}

Department of Microbiology and Immunology, Witebsky Center for Microbial Pathogenesis and Immunology, University at Buffalo, Buffalo, NY, USA

\section{Edited by:}

Ed C. Lavelle, Trinity College Dublin, Ireland

\section{Reviewed by:}

Ali M. Harandi, University of

Gothenburg, Sweden

J. Rodrigo Mora, Harvard Medical

School, USA

Jiri Mestecky, University of Alabama

at Birmingham, USA

*Correspondence:

MichaelW. Russell, Department of Microbiology and Immunology,

University at Buffalo, Farber 138, 3435

Main Street, Buffalo, NY 14214, USA.

e-mail: russellm@buffalo.edu

${ }^{\dagger}$ Present address:

Brandon Feinen, FDA/CBER/OVRR/

DBPAP/LRSP, 29 Lincoln Drive,

Bethesda, MD 20892, USA.

email: brandon.feinen@fda.hhs.gov
Murine genital tract infection with Neisseria gonorrhoeae has previously been found to induce IL-17 which is important in both recruitment of neutrophils and prompt clearance of the infection. As IL-22 is another Th17-related cytokine that has been implicated in the immune responses in several infection models, we investigated its role in vaginal gonococcal infection of mice. Production of IL-22 was observed in response to stimulation with $N$. gonorrhoeae in both mouse splenic mononuclear cells and vaginal tissue explants cultured ex vivo. Tissue from mice genetically deficient in IL-22 showed diminished production of IL-6 and the CXC chemokine KC in response to N. gonorrhoeae, whereas IL-17 and the chemokines LIX and MIP-2 $\alpha$ were produced to the same extent as in wild-type tissue. IL-22-deficient mice were unexpectedly resistant to genital tract infection with $\mathrm{N}$. gonorrhoeae in vivo, but showed no change in the influx of neutrophils to the site of infection. These results reveal divergent roles for IL-17 and IL-22 in response to gonococcal infection.

Keywords: interleukin-22, immune response, Neisseria gonorrhoeae, genital infection, mouse

\section{INTRODUCTION}

Neisseria gonorrhoeae is an exclusively human pathogen that has probably been associated with humans for many millennia, and consequently has become extremely well adapted to survival within its host. Although it can infect any exposed mucosal surface, it is mainly a sexually transmitted infection of the genital tract. Typically the infection elicits an acute inflammatory response marked by an influx of neutrophils, although clinically inapparent cervical infection can persist for prolonged periods in women, so that timely treatment may not be sought. In men urethral infection usually becomes symptomatic within a few days, prompting presentation for treatment. If left untreated, cervical infection can ascend into the upper reproductive tract, causing pelvic inflammatory disease and leading to tubal scarring, infertility, and risk for ectopic pregnancy (Hook and Handsfield, 1999). The infection has usually been treated effectively with antibiotics, but there are now concerns that strains of $N$. gonorrhoeae are emerging with resistance to multiple classes of antibiotics (Allen et al., 2011). Repeated infections are common, and no state of protective immunity appears to develop as a consequence of infection. Thus the immune response to $N$. gonorrhoeae has been somewhat puzzling.

Recently we have reported that, in a mouse model of female genital tract infection, $N$. gonorrhoeae induces the production of IL-17 which has an important role in directing host response including the neutrophil influx (Feinen et al., 2010). Moreover, abrogation of signaling through the principal IL-17 receptor, IL-17RA, in IL-17RA-knockout (ko) mice results in a diminished neutrophil influx and prolongation of the infection (Feinen et al., 2010). However, it is unlikely that clearance of the infection depends on phagocytosis by neutrophils; other factors induced by IL-17 may be responsible for this (reviewed in Liu et al., 2011; Packiam et al., 2011).

Interleukin-22, a member of the IL-10 family of cytokines, is also secreted by Th17 cells (Liang et al., 2006), as well as by a subset of natural killer cells (designated NK22; Cupedo et al., 2009) and even by some Th1 cells (Duhen et al., 2009). Other studies have suggested that a distinct Th22 lineage of cells exists (Eyerich et al., 2009; Fujita et al., 2009). Many of the same cytokines that induce differentiation and proliferation of IL-17producing cells also lead to the secretion of IL-22 by Th17 cells, NK22 cells, and putative Th22 cells, including IL-6, IL-23, IL$1 \beta$, TGF $\beta$, and TNF $\alpha$ (reviewed in Wolk et al., 2010). IL-17 and IL-22 are therefore frequently produced together in response to infections.

Interleukin-22 interacts with a heterodimeric receptor, IL10R2/IL-22R1 (Wolk et al., 2004), which is expressed on a variety of non-lymphoid cells, especially epithelial cells, and ligation of this receptor leads to both protective and detrimental effects. In synergy with IL-17, IL-22 induces proinflammatory cytokines in human bronchial epithelial cells (Aujla et al., 2008) and colonic myofibroblasts (Andoh et al., 2005). Independently or in synergy with IL-17, IL-22 acts in defense against intestinal infection of mice with Citrobacter rodentium (Zheng et al., 2008). In this model, IL-22 was produced earlier in the infection than IL-17, and was essential for clearance of the bacteria and survival of the 
animals, while IL-17 was dispensable. Blockade of IL-22 downregulates the expression of CXC chemokines which are involved in the recruitment of neutrophils in response to infection with Klebsiella pneumoniae (Aujla et al., 2008). IL-22 appears to have a particularly important role in inducing epithelial cells to secrete antibacterial proteins, including $\beta$-defensins, S100 proteins, RegIII $\gamma$, and lipocalin-2 (Ouyang and Valdez, 2008).

We previously found that IL-22 was among the Th17 cytokines produced by explants of mouse vaginal tissue cultured in vitro with $N$. gonorrhoeae (Feinen et al., 2010). We hypothesized that production of IL-22 is an important component of the response to $N$. gonorrhoeae and is essential for the recruitment of innate defense mechanisms against it including neutrophils and soluble antibacterial factors. We have therefore investigated further the production of IL-22 by murine lymphocytes in response to stimulation with $N$. gonorrhoeae, and have examined its role in gonococcal genital tract infection using IL-22-ko mice, anticipating that the course of infection would be prolonged in the absence of IL-22, as we had found for interference with IL-17RA-dependent signaling.

\section{MATERIALS AND METHODS}

\section{MICE AND VAGINAL INFECTION MODEL}

Wild-type (WT) C57BL/6 and BALB/c mice were obtained from Harlan Sprague Dawley (Indianapolis, IN, USA). Breeding pairs of IL-22-ko mice on a C57BL/6 background were provided by Genentech (South San Francisco, CA, USA) and bred in the Laboratory Animal Facility of the University at Buffalo. Mice were maintained in HEPA-filtered cages with autoclaved food, water, and bedding. All procedures were performed in accordance with protocols approved by the Institutional Animal Care and Use Committee, and in compliance with all applicable laws and guidelines.

For the vaginal gonococcal infection model (Jerse, 1999), agedmatched groups of 10 female C57BL/6 WT and IL-22-ko mice, between 8 and 10 weeks of age and in anestrus or diestrus, were injected with estradiol on days $-2,0$, and 2, and commenced on an antibiotic regimen as described previously (Feinen et al., 2010). On day 0 , mice were infected by intravaginal instillation of $20 \mu \mathrm{l}$ of phosphate-buffered saline containing $2 \times 10^{6}$ colony-forming units (CFU) of piliated $\mathrm{Opa}^{+}$N. gonorrhoeae strain FA1090 that had been freshly harvested from GC agar plates supplemented with hemoglobin and IsoVitalex, as described (Feinen et al., 2010). Infection was monitored daily by vaginal swabbing and serial dilution of the recovered mucus on chocolate agar plates containing selective antibiotics, which were incubated overnight at $37^{\circ} \mathrm{C}$ in $5 \% \mathrm{CO}_{2}$ /air (Feinen et al., 2010). Replicate cultures were also performed on brain-heart infusion agar for the commensal microbiota, and any mice that developed an overgrowth of commensals were promptly removed from experiment, leaving no fewer than seven mice per group. Duplicate swabs were smeared onto glass slides, stained with Hema 3 (Fisher Scientific), and examined microscopically to count the numbers of neutrophils relative to 100 epithelial cells.

\section{SPLEEN CELL CULTURE}

Mononuclear cells were isolated from BALB/c mouse spleens by centrifugation on Histopaque 1083 (Sigma, St. Louis, MO, USA) and cultured in 24-well plates at a density of $2 \times 10^{6}$ cells $/ \mathrm{ml}$ in RPMI 1640 supplemented with $10 \%$ fetal calf serum at $37^{\circ} \mathrm{C}$ in $5 \% \mathrm{CO}_{2}$ /air. Cultures were stimulated by adding $N$. gonorrhoeae FA1090 cells $\left(2 \times 10^{7} \mathrm{CFU} / \mathrm{ml}\right)$, gonococcal outer membrane vesicles (OMV; $5 \mu \mathrm{g} / \mathrm{ml}$ ), obtained by shearing $N$. gonorrhoeae FA1090 cells in lithium acetate buffered as described (Feinen et al., 2010), or ConA $(2 \mu \mathrm{g} / \mathrm{ml})$. Supernatants were harvested after 3 days, and IL-22 was assayed by ELISA using a kit obtained from eBioscience (San Diego, CA, USA).

\section{VAGINAL EXPLANTS}

Vaginas were excised aseptically from WT or IL-22-ko C57BL/6 mice, and fragments of approximately $10 \mathrm{mg}$ were cultured in RPMI 1640 supplemented with $10 \%$ fetal calf serum, $2 \mathrm{mM}$ glutamine, $10 \mathrm{mM}$ HEPES, penicillin, streptomycin, and fungizone, as described previously (Feinen et al., 2010). Cultures were stimulated with $N$. gonorrhoeae at a concentration of $2 \times 10^{7} \mathrm{CFU} / \mathrm{ml}$, prepared as described above. Supernatants were removed after 3 days and assayed for IL-6, IL-17, IL-22, LIX, KC, and MIP- $2 \alpha$ by means of ELISA using reagents and kits obtained from eBioscience or R\&D Systems (Minneapolis, MN, USA).

\section{STATISTICS}

Statistical analysis was performed using InStat 3 or Prism 5 (GraphPad Software, San Diego, CA, USA). Student's $t$ or twoway ANOVA with Bonferroni post hoc test were used to determine the significance of difference of means. Kaplan-Meier survival analysis with the log-rank test was used to evaluate the duration of infection in animals. $P<0.05$ in two-tailed tests was considered significant.

\section{RESULTS}

To determine whether $N$. gonorrhoeae can induce production of IL-22 from murine immune cells, splenic mononuclear cells were cultured with or without $N$. gonorrhoeae or OMV, which we had previously shown to replicate stimulation with live $N$. gonorrhoeae (Feinen et al., 2010), or with ConA as a positive control. As observed previously for IL-17, IL-22 was secreted into the supernatants of cells cultured with live gonococci or OMV (Figure 1). This result indicates that mononuclear cell populations from mice are capable of producing IL-22 in response to $N$. gonorrhoeae, without requiring additional factors from infected tissue.

We have previously shown that mouse vaginal explants produced IL-22 in response to $N$. gonorrhoeae in an ex vivo culture model, and that generation of IL-22 was independent of signaling through IL-17RA (Feinen et al., 2010). To expand on this finding, mouse vaginal explants from either WT or IL-22-ko mice were cultured alone or with $N$. gonorrhoeae, and the secretion of inflammatory cytokines and CXC chemokines into the supernatants was determined by ELISA. The results confirmed that IL-22 was produced by WT vaginal tissue in response to $N$. gonorrhoeae, but no IL-22 was detected in the supernatants of vaginal explants obtained from IL-22-ko mice (Figure 2). The IL-22-ko explants also showed unaltered IL-17 production relative to explants from WT mice, although generation of IL-6 was significantly diminished (Figure 2). In addition, production of the chemokine KC (CXCL1) in response to N. gonorrhoeae was diminished in IL-22-ko tissue, 


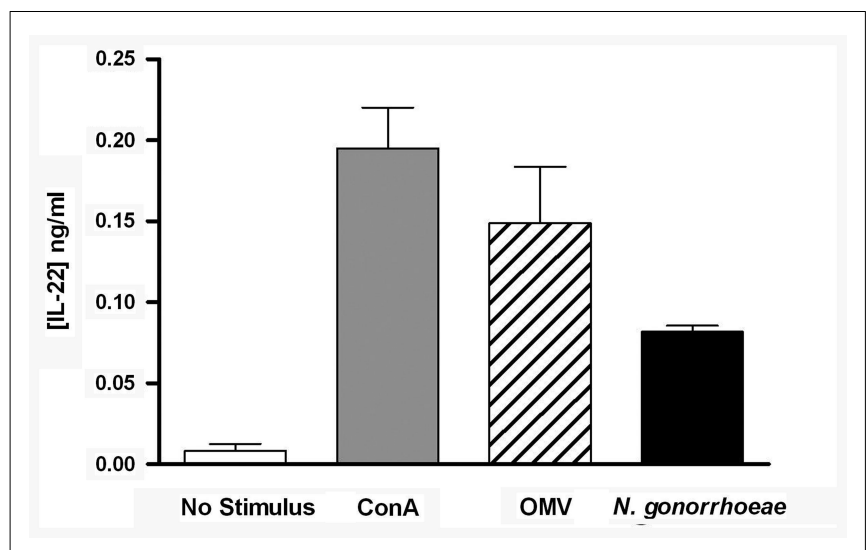

FIGURE 1 | Production of IL-22 from mouse splenic mononuclear cells, incubated in medium only (control), ConA $(2 \mu \mathrm{g} / \mathrm{ml}), N$. gonorrhoeae $\left(2 \times 10^{7} \mathrm{CFU} / \mathrm{ml}\right)$, or gonococcal OMV $(5 \mu \mathrm{g} / \mathrm{ml})$ for 3 days. Supernatants were assayed for IL-22 by ELISA. Data are shown as mean $\pm S D, N=3$, from one of three experiments yielding similar results.

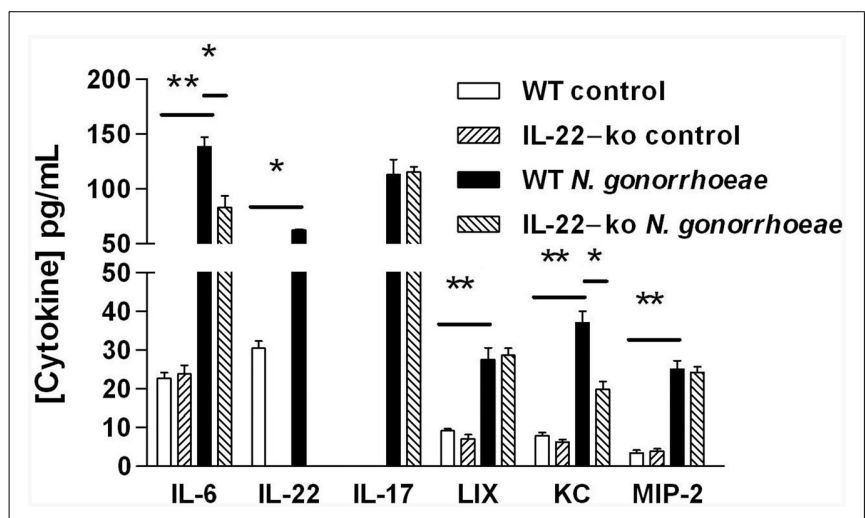

FIGURE 2 | Production of cytokines and chemokines by mouse vaginal explants cultured with $\boldsymbol{N}$. gonorrhoeae. Vaginal tissue from WT or IL-22-ko mice was incubated in vitro in medium only (control) or with $\mathrm{N}$. gonorrhoeae at a concentration of $2 \times 10^{7} \mathrm{CFU} / \mathrm{ml}$. Supernatants were assayed after 3 days for cytokines and chemokines by ELISA. Results are shown as mean $\pm \mathrm{SD}$ of triplicate cultures. Cytokine or chemokine production by WT tissue in the presence of $N$. gonorrhoeae was significantly higher than in corresponding controls, or than by IL-22-ko tissue in the presence of $N$. gonorrhoeae, as indicated by the bars: ${ }^{*} P<0.01$; ${ }^{*} P<0.05$ (Student's $t$ )

whereas production of MIP-2 $\alpha$ (CXCL2) and LIX (CXCL5) were unaltered (Figure 2 ). These results suggested that IL-22 could be involved in neutrophil recruitment in response to $N$. gonorrhoeae.

To determine whether production of IL-22 is important in the clearance of gonococcal infection and neutrophil recruitment into the genital tract, we compared the course of infection and neutrophil response in WT and IL-22-ko mice. Female mice were pretreated with estradiol and antibiotics to suppress the indigenous vaginal microbiota, and challenged intravaginally with $N$. gonorrhoeae. Vaginal swabs were collected daily for gonococcal culture, and smears were made and stained for microscopic evaluation of infiltrating neutrophils relative to epithelial cells. The experiment was performed three times to confirm the results.

In complete contrast to our previous findings in IL-17RA-ko mice (Feinen et al., 2010), the infection was cleared much faster in IL-22-ko mice compared to WT mice (Figure 3). Whereas in WT mice the numbers of recoverable gonococci began to decrease from about day 4 and the infection was cleared in all animals by day 8 , similar to previous findings (Feinen et al., 2010), in IL-22-ko mice the infection began to decrease after day 1 , and was completely cleared in all animals by day 4 (Figures 3A,B). The neutrophil influx followed the same course in both groups until day 5 , after which it leveled off in the IL-22-ko mice and continued to rise in the WT mice, probably in ongoing response to the infection in these animals (Figure 3C).

\section{DISCUSSION}

We found that the production of IL-22 is a component of the murine response to $N$. gonorrhoeae, both in vitro and in vivo. Normal mouse spleen cells or explants of vaginal tissue stimulated with gonococci released IL-22 into the supernatants. Secretion of IL-22 was also detected when iliac lymph node or vaginal cells isolated from mice infected with $N$. gonorrhoeae were cultured in vitro (Liu et al., 2012). Given that IL-22 is known to be produced by Th17 cells (Liang et al., 2006), and that N. gonorrhoeae induces IL-17 and a Th17 response (Feinen et al., 2010) this is not surprising. However, early production of IL-22 in response to N. gonorrhoeae infection suggests that it may originate from cells other than those of the Th17 lineage. IL-22 has been demonstrated in the response to other murine models of infection, such as K. pneumoniae and C. rodentium (Aujla et al., 2008; Zheng et al., 2008); indeed in these models, IL-22 appears to have a more prominent role in protection than IL-17. Whereas IL-17 induces the recruitment of neutrophils to sites of infection, through the production of cytokines such as GCSF which mobilizes neutrophils from bone marrow reserves and of CXC chemokines which attract neutrophils (Ouyang et al., 2008), IL-22 targets epithelial cells to upregulate the production of several antimicrobial peptides including $\beta$-defensins, S100 proteins, lipocalin-2, and RegIII $\gamma$ (Ouyang and Valdez, 2008). Blockade or deletion of IL-22 inhibits the production of these factors and enhances the survival of $K$. pneumoniae and $C$. rodentium (Aujla et al., 2008; Zheng et al., 2008).

We therefore expected that vaginal gonococcal infection of IL22-ko mice would result in increased recovery of $N$. gonorrhoeae and delayed clearance of infection, as we found in IL-17RA-ko mice. Instead, we found the complete opposite: numbers of $N$. gonorrhoeae recoverable from the genital tract of infected IL-22ko mice declined rapidly from day 1 after inoculation, and the infection was completely cleared by day 4 . The rapid fall in recoverable gonococci suggests that the inoculum failed to take hold in these animals, whereas in normal WT mice the infection persists with evidence for growth and phase-variation of Opa protein expression (Jerse, 1999; Simms and Jerse, 2006). Production of other cytokines in response to gonococcal stimulation of vaginal explants, IL-6 and the chemokine KC (CXCL1), was also diminished in tissues from IL-22-ko mice, but notably the production of IL-17 and chemokines MIP-2 $\alpha$ (CXCL2) and LIX (CXCL5) were not affected. The impact on CXC chemokines was the opposite of 


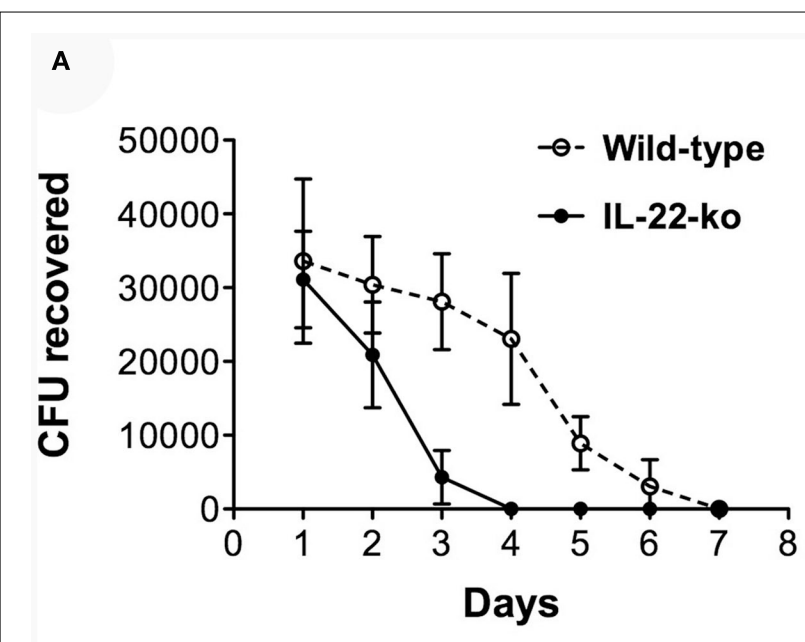

B

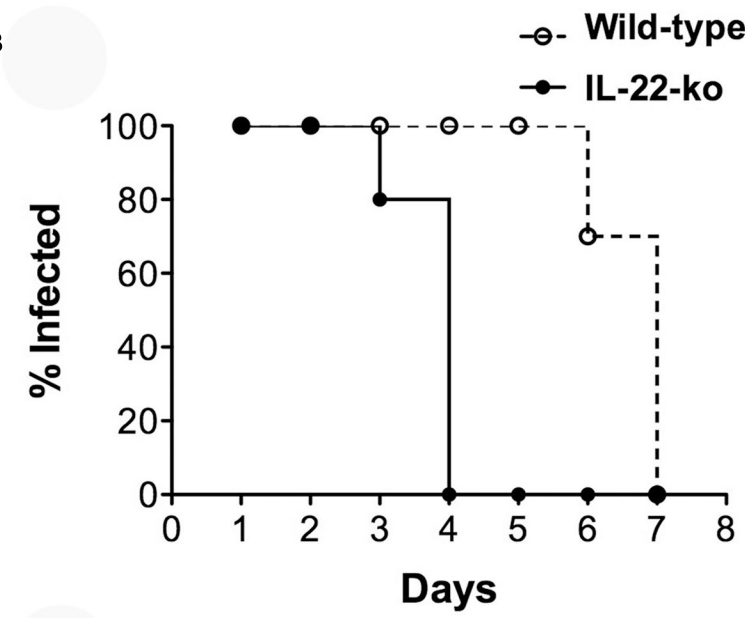

C

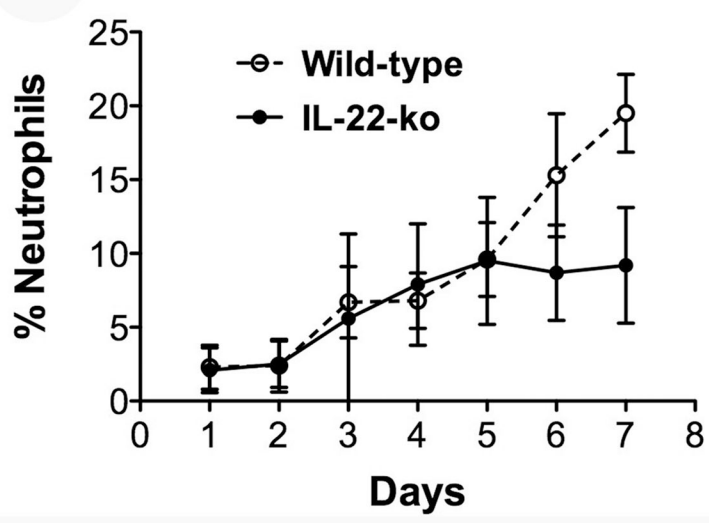

FIGURE 3 | Shortened duration of vaginal gonococcal infection in IL-22-ko mice. IL-22-ko or WT C57BL/6 mice (10 per group) were infected vaginally with $N$. gonorrhoeae on day 0 ; infection was monitored by vaginal swab culture, and the neutrophil influx was determined by microscopic examination of vaginal smears. (A) Number of recoverable N. gonorrhoeae (mean $\pm \mathrm{SD}, \mathrm{CFU} /$ mouse); (B), percentage of mice remaining infected each day $(P<0.001$; Kaplan-Meier); (C), neutrophils relative to epithelial cells (mean $\pm \mathrm{SD}, \%)$. Data shown from one of three experiments yielding similar results. the effect of IL-17RA deficiency, in which production of MIP-2 $\alpha$ and LIX were abrogated while that of $\mathrm{KC}$ was unaffected (Feinen et al., 2010). In addition, there was no observable change in neutrophil influx in response to gonococcal infection of IL-22-ko mice at least until after the infection was cleared, suggesting there is some redundancy in the chemokines involved in recruiting neutrophils into the genital tract.

The biological activities of IL-22 are complex (Sonnenberg et al., 2011). There is strong evidence for its importance in mediating innate mucosal defense by inducing the production of antimicrobial proteins by mucosal epithelial cells (Ouyang and Valdez, 2008), and IL-22 cooperates with IL-17 in protection against bacterial infections (Aujla et al., 2008; Zheng et al., 2008). However, IL-22 interacts with IL-17 in a complex manner. In a model of sterile airway inflammation induced by bleomycin, IL-22 could be either proinflammatory or protective, depending upon the presence or absence of IL-17 respectively (Sonnenberg et al., 2010). In this model IL-17A also inhibited the production of IL-22 by Th17 cells. In skin IL-22 induces production of antimicrobial peptides and affects the differentiation and proliferation of skin cells, indicating a role in wound healing and tissue rearrangement (Boniface et al., 2005). In addition, IL-22 is implicated in epithelial repair, and has been shown to contribute significantly to the inflammatory skin condition, psoriasis (Wolk et al., 2009). IL-22 is also involved in systemic innate immune defense against some bacteria (Siegemund et al., 2009). However, immune defense against Listeria monocytogenes is independent of IL-22 (Zenewicz et al., 2007), and IL-22 has only a minimal role in defense against oropharyngeal Candida albicans (Conti et al., 2009). In polymicrobial sepsis neutralization of IL-22 enhances the influx of phagocytes and diminishes bacterial loads (Weber et al., 2007). Clearly, IL-22 has divergent roles in immune defense against various infections.

We therefore propose an alternative explanation for our findings, and hypothesize that IL-22 is necessary to create the conditions for gonococcal infection of the murine genital tract, such that in its absence, N. gonorrhoeae is unable to establish infection. This is in accordance with our observations. We have further hypothesized that $N$. gonorrhoeae proactively induces in its host Th17-driven innate responses that it is capable of resisting and concomitantly suppresses $\mathrm{Th} 1 / \mathrm{Th} 2$ adaptive immune responses that might be capable of eliminating it (Liu et al., 2011). We have evidence to support this hypothesis in the murine model (Feinen et al., 2010; Liu and Russell, 2011; Liu et al., 2012). It is also possible that IL-17-governed inflammatory responses induced by $N$. gonorrhoeae might facilitate its infection of the mouse vagina by suppressing competing organisms that are susceptible to innate defense factors, to which gonococci are relatively resistant, as has been shown for Salmonella enterica Typhimurium infection of the mouse intestine (Raffatellu et al., 2009).

It is not known what is responsible for the eventual clearance of N. gonorrhoeae from the murine genital tract, and it should be noted that the mouse is not its natural host. Most probably, as $N$. gonorrhoeae is an exclusively human pathogen, numerous factors limit its ability to persist in the murine genital tract. These include species-specificity in recognition of receptors for gonococcal colonization factors and of transferrin as an iron source, as well as selective resistance to human complement (reviewed in Jerse et al., 
2011). Although in our experiments clearance follows the neutrophil influx (Feinen et al., 2010), this is not proof of causation, and other studies indicate that neutrophils cannot be responsible for clearance (Packiam et al., 2010, 2011). Thus the apparent association of prolonged infection with abrogation of the neutrophil influx in IL-17RA-ko mice may be misleading, because the infection is still cleared after a delay of several days despite the absence of a neutrophil influx (Feinen et al., 2010). It may be that in the absence of IL-17 (or deficiency of IL-17RA), other defense factors were diminished despite the generation of IL-22, whereas in

\section{REFERENCES}

Allen, V. G., Farrell, D. J., Rebbapragada, A., Tan, J., Tijet, N., Perusini, S. J., Towns, L., Lo, S., Low, D. E., and Melano, R. G. (2011). Molecular analysis of antimicrobial resistance mechanisms in Neisseria gonorrhoeae isolates from Ontario, Canada. Antimicrob. Agents Chemother. (Bethesda) 55, 703-712.

Andoh, A., Zhang, Z., Inatomi, O., Fujino, S., Deguchi, Y., Araki, Y., Tsujikawa, T., Kitoh, K., KimMitsuyama, S., Takayanagi, A., Shimizu, N., and Fujiyama, Y. (2005). Interleukin-22, a member of the IL-10 subfamily, induces inflammatory responses in colonic subepithelial myofibroblasts. Gastroenterology 129, 969-984.

Aujla, S. J., Chan, Y. R., Zheng, M., Fei, M., Askew, D. J., Pociask, D. A., Reinhart, T. A., McAllister, F., Edeal, J., Gaus, K., Husain, S., Kreindler, J. L., Dubin, P. J., Pilewski, J. M., Myerburg, M. M., Mason, C. A., Iwakura, Y., and Kolls, J. K. (2008). IL-22 mediates mucosal host defense against Gram-negative bacterial pneumonia. Nat. Med. 14, 275-281.

Boniface, K., Bernard, F. X., Garcia, M., Gurney, A. L., Lecron, J. C., and Morel, F. (2005). IL22 inhibits epidermal differentiation and induces proinflammatory gene expression and migration of human keratinocytes. J. Immunol. 174, 3695-3702.

Conti, H. R., Shen, F., Nayyar, N., Stocum, E., Sun, J. N., Lindemann, M. J., Ho, A. W., Hai, J. H., Yu, J. J., Jung, J. W., Filler, S. G., MassoWelch, P., Edgerton, M., and Gaffen, S. L. (2009). Th17 cells and IL17 receptor signaling are essential for mucosal host defense against oral candidiasis. J. Exp. Med. 206, 299-311.

Cupedo, T., Crellin, N. K., Papazian, N., Rombouts, E. J., Weijer, K., Grogan, J. L., Fibbe, W. E., Cornelissen, J. J., and Spits, H. (2009). Human fetal lymphoid tissue-inducer cells are interleukin 17-producing precursors to RORC+ CD127+ natural killer-like cells. Nat. Immunol. 10, 66-74.

Duhen, T., Geiger, R., Jarrossay, D., Lanzavecchia, A., and Sallusto, F. (2009). Production of interleukin 22 but not interleukin 17 by a subset of human skin-homing memory T cells. Nat. Immunol. 10, 857-863.

Eyerich, S., Eyerich, K., Pennino, D., Carbone, T., Nasorri, F., Pallotta, S., Cianfarani, F., Odorisio, T., Traidl-Hoffmann, C., Behrendt, H., Durham, S. R., Schmidt-Weber, C. B., and Cavani, A. (2009). Th22 cells represent a distinct human $\mathrm{T}$ cell subset involved in epidermal immunity and remodeling. J. Clin. Invest. 119, 3573-3585.

Feinen, B., Jerse, A. E., Gaffen, S. L., and Russell, M. W. (2010). Critical role of Th17 responses in a murine model of Neisseria gonorrhoeae genital infection. Mucosal Immunol. 3, 312-321.

Fujita, H., Nograles, K. E., Kikuchi, T., Gonzalez, J., Carucci, J. A., and Krueger, J. G. (2009). Human Langerhans cells induce distinct IL22-producing CD4+ T cells lacking IL-17 production. Proc. Natl. Acad. Sci. U.S.A. 106, 21795-21800.

Hook, E. W., and Handsfield, H. H. (1999). "Gonococcal infections in the adult," in Sexually Transmitted Diseases, 3rd Edn, eds K. K. Holmes, P. F. Sparling, P.-A. Mårdh, S. M. Lemon, W. E. Stamm, P. Piot, and J. $\mathrm{N}$. Wasserheit (New York: McGrawHill), 451-466.

Jerse, A. E. (1999). Experimental gonococcal genital tract infection and opacity protein expression in estradiol-treated mice. Infect. Immun. 67, 5699-5708.

Jerse, A. E., Wu, H., Packiam, M., Vonck, R. A., Begum, A. A., and Garvin, L. E. (2011). Estradiol-treated female mice as surrogate hosts for Neisseria gonorrhoeae genital tract infections. Front. Microbiol. 2:107. doi:10.3389/fmicb.2011.00107

the absence of IL-22 (but presence of IL-17) gonococcal infection of the mouse genital tract could not occur. In that way, perhaps IL-22 deficiency is more informative than IL-17RA deficiency in demonstrating how $N$. gonorrhoeae exploits host Th17 responses to create an environment favorable for its survival.

\section{ACKNOWLEDGMENTS}

Studies in the authors' laboratory were supported by USPHS grant AI074791 from the National Institute of Allergy and Infectious Diseases, and the John R. Oishei Foundation, Buffalo, NY, USA.

Liang, S. C., Tan, X. Y., Luxenberg, D. P. Karim, R., Dunussi-Joannopoulos, K., Collins, M., and Fouser, L. A (2006). Interleukin (IL)-22 and IL17 are coexpressed by Th 17 cells and cooperatively enhance expression of antimicrobial peptides. J. Exp. Med. 203, 2271-2279.

Liu, Y., Feinen, B., and Russell, M. W. (2011). New concepts in immunity to Neisseria gonorrhoeae: innate responses and suppression of adaptive immunity favor the pathogen, not the host. Front. Microbiol. 2:52. doi:10.3389/fmicb.2011.00052

Liu, Y., Islam, E., Jarvis, G. A., GrayOwen, S., and Russell, M. W. (2012). Neisseria gonorrhoeae selectively suppresses the development of Th1 and Th2 cells, and enhances Th17 cell responses, through TGF( $\beta$-dependent mechanisms. Mucosa Immunol. 5. (in press).

Liu, Y., and Russell, M. W. (2011). Diversion of the immune response to Neisseria gonorrhoeae from Th17 to Th1/Th2 by treatment with antiTGF- $\beta$ antibody generates immunological memory and protective immunity. mBio 2, e00095-11.

Ouyang, W., Kolls, J. K., and Zheng, Y. (2008). The biological functions of $\mathrm{T}$ helper 17 cell effector cytokines in inflammation. Immunity 28, 454-467.

Ouyang, W., and Valdez, P. (2008). IL22 in mucosal immunity. Mucosal Immunol. 1, 335-338.

Packiam, M., Veit, S. J., Anderson, D. J., Ingalls, R. R., and Jerse, A. E. (2010). Mouse strain-dependent differences in susceptibility to Neisseria gonorrhoeae infection and induction of innate immune responses. Infect. Immun. 78, 433-440.

Packiam, M., Wu, H., Veit, S. J., Mavrogiorgos, N., Jerse, A. E., and Ingalls, R. R. (2011). Protective role of Toll-like receptor 4 in experimental gonococcal infection of female mice. Mucosal Immunol. 4, 2011.2038.

Raffatellu, M., George, M. D., Akiyama, Y., Hornsby, M. J., Nuccio, S.-P.,
Paixao, T. A., Butler, B. P., Chu, H., Santos, R. L., Berger, T., Mak, T. W., Tsolis, R. M., Bevins, C. L., Solnick, J. V., Dandekar, S., and Bäumler, A. J. (2009). Lipocalin2 resistance confers an advantage to Salmonella enterica serotype Typhimurium for growth and survival in the inflamed intestine. Cell Host Microbe 5, 476-486.

Siegemund, S., Schutze, N., Schulz, S., Wolk, K., Nasilowska, K. Straubinger, R. K., Sabat, R., and Alber, G. (2009). Differential IL-23 requirement for IL-22 and IL-17A production during innate immunity against Salmonella enterica serovar Enteritidis. Int. Immunol. 21, 555-565.

Simms, A. N., and Jerse, A. E. (2006). In vivo selection for Neisseria gonorrhoeae opacity protein expression in the absence of human carcinoembryonic antigen cell adhesion molecules. Infect. Immun. 74, 2965-2974.

Sonnenberg, G. F., Fouser, L. A., and Artis, D. (2011). Border patrol: regulation of immunity, inflammation and tissue homeostasis at barrier surfaces by IL-22. Nat. Immunol. 12 , 383-390.

Sonnenberg, G. F., Nair, M. G., Kirn, T. J., Zaph, C., Fouser, L. A., and Artis, D. (2010). Pathological versus protective functions of IL-22 in airway inflammation are regulated by IL-17A. J. Exp. Med. 207, 1293-1305. Weber, G. F., Schlautkotter, S., KaiserMoore, S., Altmayr, F., Holzmann B., and Weighardt, H. (2007). Inhibition of interleukin-22 attenuates bacterial load and organ failure during acute polymicrobial sepsis. Infect. Immun. 75, 1690-1697.

Wolk, K., Haugen, H. S., Xu, W., Witte, E., Waggie, K., Anderson, M., Vom Baur, E., Witte, K., Warszawska, K. Philipp, S., Johnson-Leger, C., Volk, H. D., Sterry, W., and Sabat, R. (2009). IL-22 and IL-20 are key mediators of the epidermal alterations in psoriasis while IL-17 and IFN-gamma are not. J. Mol. Med. (Berl.) 87, 523-536. 
Wolk, K., Kunz, S., Witte, E., Friedrich, M., Asadullah, K., and Sabat, R. (2004). IL-22 increases the innate immunity of tissues. Immunity 21, 241-254.

Wolk, K., Witte, E., Witte, K., Warszawska, K., and Sabat, R. (2010). Biology of interleukin-22. Semin. Immunopathol. 32, 17-31.

Zenewicz, L. A., Yancopoulos, G. D., Valenzuela, D. M., Murphy, A. J., Karow, M., and Flavell, R. A. (2007). Interleukin-22 but not interleukin-17 provides protection to hepatocytes during acute liver inflammation. Immunity 27, 647-659.

Zheng, Y., Valdez, P. A., Danilenko, D. M., Hu, Y., Sa, S. M., Gong, Q., Abbas, A. R., Modrusan, Z., Ghilardi, N., de Sauvage, F. J., and Ouyang, W. (2008). Interleukin22 mediates early host defense against attaching and effacing bacterial pathogens. Nat. Med. 14, 282-289.
Conflict of Interest Statement: The authors declare that the research was conducted in the absence of any commercial or financial relationships that could be construed as a potential conflict of interest.

Received: 14 October 2011; accepted: 18 January 2012; published online: 06 February 2012

Citation: Feinen B and Russell MW (2012) Contrasting roles of $I L-22$ and IL-17 in murine genital tract infection by Neisseria gonorrhoeae. Front. Immun 3:11. doi: 10.3389/fimmu.2012.00011

This article was submitted to Frontiers in Mucosal Immunity, a specialty of Frontiers in Immunology.

Copyright (c) 2012 Feinen and Russell. This is an open-access article distributed under the terms of the Creative Commons Attribution Non Commercial License, which permits non-commercial use, distribution, and reproduction in other forums, provided the original authors and source are credited. 